\title{
NA TRILHA DA ALIMENTAÇÃO: PROMOVENDO A REFLEXÃO SOBRE HÁBITOS ALIMENTARES SAUDÁVEIS NA ESCOLA
}

\author{
ON THE FOOD TRAIL: PROMOTING REFLECTION ABOUT HEALTHY FOOD \\ HABITS IN SCHOOL
}

\author{
SANTOS, Filipe Pessoa dos ${ }^{1}$ \\ RAMOS, Paula ${ }^{2}$ \\ GIANNELLA, Tais Rabetti ${ }^{3}$ \\ STRUCHINER, Miriam ${ }^{4}$
}

\begin{abstract}
RESUMO
A alimentação contemporânea é marcada pela difusão de alimentos ultraprocessados e pela alimentação fora de casa, consequências do ritmo acelerado da vida predominantemente urbanizada. É importante reconhecer o espaço escolar como privilegiado para o desenvolvimento de atividades de educação alimentar e nutricional para promoção da saúde e formação de hábitos saudáveis. Neste sentido, este artigo tem como objetivo apresentar a oficina "Na trilha da alimentação" desenvolvida no contexto de um projeto de extensão em uma Escola Municipal que atende ao Ensino Fundamental II. A oficina integrou três atividades, cujo objetivo foi problematizar a relação da alimentação com a saúde, detalhadas ao longo do trabalho: (1) Diário do corpo; (2) Desvendando os alimentos; (3) Aproveitamento integral dos alimentos. Participaram aproximadamente 54 alunos do ensino fundamental II. Verificou-se que os alunos apresentaram grande interesse em conhecer melhor aquilo que consomem e os impactos gerados na saúde.
\end{abstract}

Palavras-chave: Hábitos Alimentares; Gastronomia; Saúde e Qualidade de Vida; Ensino Fundamental.

\footnotetext{
${ }^{1}$ Universidade Federal do Rio de Janeiro - UFRJ / Instituto Nutes. Rio de Janeiro, RJ, Brasil. ORCID: https://orcid.org/0000-0002-9130-0118. e-mail: filipe.p2s@gmail.com

${ }^{2}$ Universidade Federal do Rio de Janeiro - UFRJ / Instituto Nutes. Rio de Janeiro, RJ, Brasil. ORCID: https://orcid.org/0000-0002-8231-1237. e-mail: paularamos.ufrj@gmail.com

${ }^{3}$ Universidade Federal do Rio de Janeiro - UFRJ / Instituto Nutes. Rio de Janeiro, RJ, Brasil. ORCID: https://orcid.org/0000-0001-9563-2964. e-mail: taisrg@yahoo.com.br

${ }^{4}$ Universidade Federal do Rio de Janeiro - UFRJ / Instituto Nutes. Rio de Janeiro, RJ, Brasil. ORCID: https://orcid.org/0000-0002-9979-2364. e-mail: miriamstru@gmail.com
} 
DOI: $10.12957 / \mathrm{e}-\mathrm{mosaicos} .2021 .48433$

\begin{abstract}
Contemporary food is characterized by the spread of ultra-processed foods and by eating out of the home, as a consequence of the fast pace of predominantly urbanized life. It is important to recognize the school space as privileged for the development of food and nutrition educational activities for the promotion of health and the formation of healthy habits. In this perspective, this article aims to present the workshop "On the food trail" developed by research groups from a public university in partnership with Madrid Municipal School. The workshop integrated three activities aiming to problematize the relationship between food and health, detailed throughout the activities: (1) Body diary; (2) Unravelling the food and (3) Full use of food. Approximately 54 elementary school students participated in the activities. We observed that students presented a great interest in knowing better about what they consume and the impacts generated on health.
\end{abstract}

KeYwORDS: Eating habits; Gastronomy; Health and Quality of Life; Elementary School.

\title{
INTRODUÇÃo
}

Muito se discute sobre alimentação, principalmente quando consideramos o aumento do número de casos de Doenças Crônicas Não Transmissíveis (DCNT), geradas pelo cenário de insegurança alimentar, bem como a cultura alimentar prevalente nos grandes centros urbanos. Diversos estudos apontam a relação da má qualidade da alimentação com o aumento da obesidade (MAZUR, NAVARRO, 2015, p. 42), de doenças cardiovasculares (SANTOS, GUBERT, DEUS, 2016, p. 1026) e diabetes (SILVA et al., 2018, p. 26), além de destacar a importância da alimentação saudável e adequada para que os que já sofrem com as DCNT não tenham seus quadros agravados (VASCONCELOS, 2015, p. 119).

Um dos aspectos que circundam esse cenário é a geração de novas necessidades inerentes à adaptação ao modo de vida urbano. Aspectos como a necessidade de praticidade, a falta de tempo e a alimentação fora de casa criam demandas para o mercado alimentício que produz, como resposta, os fast-foods e os alimentos ultraprocessados. Esses alimentos, além de oferecerem praticidades, são, por muitas vezes, adquiridos por um baixo custo, o que contribui para que eles se tornem, cada vez mais, escolhas predominantes perante a lógica da vida moderna (GARCIA, 2003, p. 484; MARTINS et al, 2013, p. 658).

Essa mudança no padrão alimentar vem se estabelecendo como uma tendência em países desenvolvidos e em desenvolvimento, onde se observa o crescimento de alimentos ultraprocessados e, ao mesmo tempo, a diminuição do consumo de alimentos in natura ou minimamente processados (GARCIA, 2003, p. 486). A alimentação contemporânea, assim, 
DOI: $10.12957 / \mathrm{e}-\mathrm{mosaicos} .2021 .48433$

se caracteriza por um perfil nutricional desfavorável, sendo rica em açúcares, gorduras, sódio e pobre em fibras (MONTEIRO et al, 2010, p. 12). Cabe destacar que a relação do consumo de ultraprocessados com as DCNT já é algo documentado em diversos estudos que apontam esta relação e apoiam recomendações para que essas substâncias sejam evitadas (LOUZADA et al, 2015, p. 9; BIELEMANN et al, 2015, p. 9).

No Brasil, essa transformação vem ocorrendo desde os anos 1980, principalmente nos centros urbanos. Nos anos 2000, se estabeleceu em todo o país como parte comum do dia a dia das famílias (MARTINS et al, 2013, p. 663). O país vem enfrentando problemas de saúde decorrentes tanto da desnutrição e deficiência de micronutrientes quanto do aumento da obesidade (VERDE, 2014, p. 1). A Pesquisa de Orçamento Familiar - POF (2008- 2009) - do IBGE revelou que uma em cada três crianças brasileiras com idade entre cinco e nove anos estão acima do peso recomendado pela Organização Mundial de Saúde (OMS). Sendo considerado um problema de Saúde Pública, o aumento da obesidade infantil está associado à permanência desse problema na vida adulta, resultando em uma futura geração de hipertensos, diabéticos, portadores de problemas renais e cardiovasculares (VERDE, 2014, p. 1; FREITAS, COELHO, RIBEIRO, 2009, p. 11).

Nesse contexto, a escola é apontada como uma instituição de educação em um sentido ampliado, reconhecida, também, como um espaço privilegiado para promoção de alimentação saudável, com potencialidade para o desenvolvimento de ações que melhorem as condições de saúde e a situação nutricional das crianças (SCHMITZ, 2008, p. 312). Além disso, também contribui para desenvolvimento de experiências que podem ser estendidas ao contexto familiar, permitindo efeitos positivos em ambientes externos à escola (ACCIOLY, 2009, p. 3; YOKOTA, 2010, p. 39).

Portanto, buscando contribuir com a educação alimentar em uma perspectiva da promoção da saúde de crianças e adolescentes, neste artigo, apresentamos a oficina de extensão "Na trilha da alimentação", realizada em uma escola na cidade do Rio de Janeiro, voltada para alunos do Ensino Fundamental II. Essa oficina, composta por três atividades, teve como objetivo problematizar a alimentação contemporânea e promover a reflexão sobre alternativas e possibilidades para a adoção de uma alimentação mais saudável. Essa oficina vem sendo desenvolvida desde 2017, passando por algumas mudanças ao longo do tempo, contudo, neste trabalho, a análise se aterá à experiência realizada, em 2019, no contexto do Dia Mundial da Saúde celebrado nesta escola.

\section{A PROMOÇÃo dA ALIMENTAÇÃo SAUdÁVEL E O PAPEL DA ESCOLA}

O desenvolvimento tecnológico que atingiu a área de produção alimentícia proporcionou transformações intensas na relação da sociedade com os alimentos. A produção em massa de determinados gêneros, assim como a ação industrial voltada para 
DOI: $10.12957 /$ e-mosaicos.2021.48433

desenvolvimento, produção e distribuição de alimentos vem fomentando a construção de uma estrutura social que envolve intensas disputas por poder no setor agroalimentar, acarretando forte ameaça à soberania alimentar (AZEVEDO, 2017, p. 287).

Partindo do princípio de que a soberania alimentar é o direito ao acesso a alimentos considerados saudáveis, justos e de boa qualidade (MEIRELLES, 2004, p. 11), foram decretadas, no ano de 2010, as diretrizes da Política Nacional de Segurança Alimentar e Nutricional - PNSAN - com o objetivo de implementar o Sistema Nacional de Segurança Alimentar e Nutricional (SISAN). Essas políticas públicas assumiram como foco a definição dos parâmetros para garantir a manutenção da soberania e segurança alimentar no Brasil, assegurando o direito humano à alimentação adequada em todo território nacional (BRASIL, 2010).

Um dos objetivos do PNSAN é "Promover ações de Educação Alimentar e Nutricional no ambiente escolar e fortalecer a gestão, execução e o controle social do PNAE, com vistas à promoção da segurança alimentar e nutricional." (CAISAN, 2011, p. 51). Já o PNAE - Programa Nacional de Alimentação Escolar - regula a alimentação escolar e constitui um dos eixos estruturantes da política de acesso aos alimentos do PNSAN. Essa política ressalta o valor e o direito a uma alimentação segura, variada, saudável e adequada que respeita valores culturais e tradicionais por meio de ações de Educação Alimentar e Nutricional (EAN) e do apoio à sustentabilidade na aquisição de gêneros alimentícios pelas escolas (BRASÍLIA, 2020).

Dessa forma, a escola ganha destaque como um espaço que ocupa um importante papel na promoção de mudanças relativas à alimentação tanto diretamente - no que se refere ao fornecimento de alimentos e refeições - quanto indiretamente com ações de educação alimentar e nutricional. Nesse sentido, Bezerra (2009, p. 104) considera que a merenda escolar carrega um significado expressivo para os sujeitos, ultrapassando a mera satisfação das necessidades biológicas. Para o autor,

Discutir comida/alimentação implica considerar outra categoria inseparável do ato de comer, notadamente quando se trata da população mais pobre: a fome. Dessa forma, as práticas relacionadas ao comer na escola atuam como elementos curriculares que vão de encontro à possibilidade de a escola pública contribuir no processo de emancipação (Oliveira, 1996) de seus alunos. (Bezerra, 2009, p.111)

O ambiente escolar é, portanto, reconhecido como espaço privilegiado para a promoção da saúde na comunidade escolar, como preconizado no conceito de "Escola Promotora de Saúde", que fomenta ações promotoras de desenvolvimento saudável e melhoria do estado nutricional dos estudantes (SCHMITZ, 2008, p. 312; GONÇALVES et al, 
DOI: $10.12957 /$ e-mosaicos.2021.48433

2008, p. 183). A autora Accioly (2009, p. 1) destaca que a escola desempenha importante papel "na formação de valores, hábitos e estilos de vida, entre eles, o da alimentação, tendo como base práticas alimentares promotoras de saúde que respeitem a diversidade cultural e que sejam ambiental, cultural, econômica e socialmente sustentáveis".

Com o foco na promoção da alimentação saudável - compatível com o conceito ampliado de saúde - compreende-se que tratar, na escola, do tema alimentação envolve discutir não apenas aspectos biológicos associados ao tema, mas problematizar condições sociais, econômicas e ambientais que envolvem a produção, o transporte e o consumo de alimentos, desigualdades sociais e de acesso aos alimentos, cultura alimentar, hábitos alimentares e as influências da cultura contemporânea (MAEYAMA et al, 2015, p. 139). Para Acciolly (2009, p. 6), é necessário tornar, efetivamente, a alimentação um tema transversal nos currículos para que seja vivenciado na prática e discutido em todas as atividades da escola, sob diferentes aspectos e incorporando sua natureza complexa. Considerada como "fato social total" (MAUSS, 1974, p.41), que envolve vários níveis de realidade em vários âmbitos (social, econômico, político, ambiental etc.), é importante que a escola aborde essa temática em sua totalidade. Principalmente, quando levamos em conta que é nos períodos da infância e da adolescência que são estabelecidos hábitos com maior possibilidade de perdurar durante a vida adulta (TRICHES; SCHNEIDER, 2010, p. 12).

\section{Metodologia}

A Oficina "Na trilha da alimentação" é desenvolvida e realizada no contexto de um projeto de extensão desenvolvido no Laboratório de Tecnologias Cognitivas (LTC) do Instituto NUTES de Educação em Ciências e Saúde. Por ser composta por três atividades independentes sobre os temas alimentação e saúde, a ideia de "trilha" se refere à possibilidade de o estudante percorrer um caminho - construído individualmente - na direção de uma alimentação saudável. A oficina foi elaborada no contexto de um projeto de extensão, cujo objetivo foi desenvolver ações de educação em saúde, em parceria com a equipe de coordenadores e de professores, em uma escola pública municipal do Rio de Janeiro. É importante ressaltar que a "Trilha" faz parte de uma atividade maior envolvendo outras temáticas - que compõe o projeto de extensão relacionado a tecnologias digitais na educação em saúde. Esse projeto vem sendo realizado há três anos em parceria com essa escola e resultou em diversas atividades junto a alunos e professores.

A escola estadual parceira localiza-se em Vila Isabel (Rio de Janeiro) e é voltada para estudantes do Ensino Fundamental II ( $6^{\circ}$ ao $9^{\circ}$ ano). Atende, aproximadamente, 600 alunos nos turnos da manhã e da tarde. A Oficina foi realizada na comemoração do Dia Mundial da Saúde, que ocorre no mês abril de 2019. Neste dia, a escola suspendeu as 
DOI: $10.12957 / \mathrm{e}-\mathrm{mosaicos} .2021 .48433$

aulas para que os alunos pudessem participar do evento, que contou com diversas atividades relacionadas ao tema saúde, organizadas em outros espaços da comunidade $e$ em outras universidades públicas. A oficina contou com três atividades (descritas adiante) que foram mediadas pelos autores deste trabalho, além de alunos de graduação, mestrado e doutorado. No total, a atividade contou com a participação de aproximadamente 54 estudantes. Para coletar as percepções dos discentes acerca da atividade, utilizamos o celular para registrar (em áudio) falas dos grupos referentes a duas perguntas feitas aos participantes, sendo elas: 1) O que mais você gostou na atividade? 2) O que você aprendeu sobre saúde e alimentação nessa atividade? Com estas perguntas, buscamos criar um espaço de diálogo e de discussão para que os estudantes pudessem refletir e associar as atividades propostas com o seu cotidiano dentro e fora da escola. Embora a análise dessas falas não seja o foco deste artigo, surgiram considerações dos participantes - aliadas às observações da equipe de desenvolvimento - que contribuíram para o desenvolvimento e a melhoria das atividades propostas.

\section{A OFICINA "NA TRILHA DA ALIMENTAÇÃO"}

A Oficina "Na trilha da alimentação" integrou três atividades - "Diário do Corpo", "Desvendando os Alimentos" e "Aproveitamento Integral dos Alimentos" - interligadas pela temática Alimentação, e que trabalhavam questões variadas sobre o tema. A seguir, as atividades desenvolvidas são detalhadas:

\section{ATIVIDADE 1) "DiáRIO dO CORPO":}

O Diário do corpo consistiu em uma atividade em que professores de educação física, que fazem parte do grupo de pesquisa, procuravam conversar com os alunos sobre a relação com o próprio corpo e o que consideram um "corpo saudável". Inicialmente, com um aluno por vez, partiram da mensuração do Índice de Massa Corporal (IMC) dos alunos, por meio de uma ferramenta desenvolvida no LTC (Fig. 1) e disponibilizada online (http://ltc-ead.nutes.ufrj.br/diariodocorpo). 
DOI: $10.12957 / \mathrm{e}-\mathrm{mosaicos} .2021 .48433$

Figura 1. A Ferramenta online desenvolvida pelo LTC para calcular o IMC

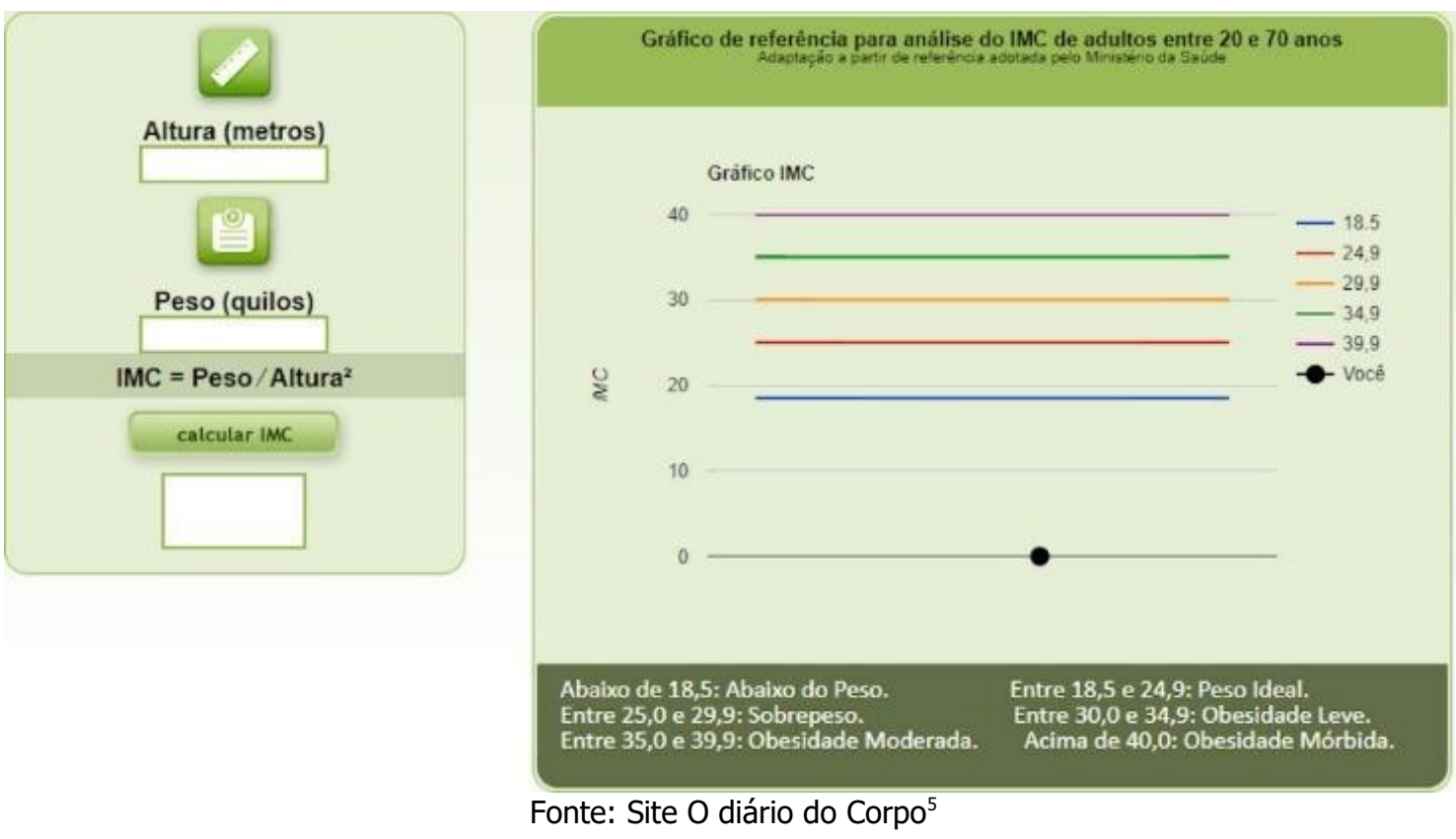

Esta medição do IMC foi um gatilho inicial para estabelecer um diálogo que buscasse problematizar os padrões estabelecidos de beleza e saúde. Será que o IMC reflete o que é um corpo saudável? Como esses padrões interferem na relação com o próprio corpo? O que é um corpo saudável? As discussões buscaram promover a reflexão sobre os padrões estéticos estabelecidos na sociedade e a relação com o corpo, além de conhecer os espaços de exercício e lazer dos alunos e discutir como essa questão tem sido tratada na família, na escola etc. Essa atividade teve como foco incentivar o olhar para o próprio corpo e buscar caminhos saudáveis e prazerosos para cuidá-lo.

No decorrer dessa atividade, os participantes puderam experimentar um momento com um ritmo mais reduzido, com um ou poucos alunos por vez, já que o assunto poderia causar constrangimento, sendo necessário um espaço de acolhimento e de escuta. Como resultado, foi possível destacar a influência de alguns fatores na construção da imagem corporal dos estudantes: (1) influência do gênero - A participação nessa atividade foi bem equânime com relação à quantidade de meninos e de meninas, porém foram as meninas que demonstraram maior entusiasmo em participar da conversa, se abrindo mais para falar sobre questões como padrões corporais e bullying. Além disso, observou-se que as meninas demonstraram maior desconforto com o próprio corpo quando comparado com os meninos, apontando desejo de emagrecimento ou insatisfação com partes dos seus corpos.

${ }^{5}$ Disponivel em: http://ltc-ead.nutes.ufrj.br/diariodocorpo 
DOI: $10.12957 / \mathrm{e}-\mathrm{mosaicos} .2021 .48433$

Gonçalves e Martínez (2014, p. 154) apontam essa realidade em seu estudo sobre imagem corporal de adolescente, destacando como resultado a prevalência da insatisfação corporal e da influência da mídia em adolescentes do sexo feminino; (2) postura da família - em alguns relatos - ficou claro que as críticas dos familiares influenciam significativamente a percepção que as crianças e os adolescentes têm do próprio corpo. Foram relatadas situações de imposição dos pais a uma alimentação restritiva e rotinas de exercícios físicos pouco prazerosas.

Del Ciampo e Del Ciampo (2010, p. 58) destacam o componente afetivo na construção de uma imagem corporal do adolescente e apontam o papel da família como crucial nesse processo. Ressaltam, contudo, que o afastamento entre o adolescente e a família, comum nessa fase, acirra a postura crítica dos pais em relação à aparência dos filhos e acarreta sentimentos negativos sobre sua autoimagem e autoestima, influenciando a qualidade de vida do adolescente; (3) disponibilidade de espaços públicos de esporte e lazer - esse foi um dos aspectos relatados pelos estudantes como obstáculo para 0 desenvolvimento de uma rotina de prática esportiva ou exercício físico regular. Essa questão remete à necessidade de se pensar a alimentação e o corpo saudável no contexto da promoção da saúde, que considere os determinantes sociais da saúde como aspectos que relacionam as desigualdades sociais com as iniquidades em saúde (MAEYAMA et al., 2015, p. 138).

\section{Atividade 2) "Desvendando os Alimentos":}

Esta atividade explorou a representação das quantidades de açúcar, sal e gordura dos alimentos processados e ultraprocessados para problematizar a alimentação contemporânea e os alimentos comumente consumidos no espaço escolar. Como ponto de partida, apresentamos aos alunos uma mesa com a disposição de alimentos processados e ultraprocessados (Fig. 2) comuns no cotidiano escolar e pedimos que escolhessem um lanche. Com base nas escolhas dos alunos, demonstramos a representação da quantidade de açúcar, de gordura e de sal contidas nesses alimentos, fazendo um contraponto com a representação dos limites diários, sugeridos pela OMS, de ingestão desses itens.

Essa representação inicial provocou discussões conduzidas de acordo com a interação e o interesse dos alunos, que incluíram a reflexão sobre a indústria de alimentos e os produtos que utilizam para conferir sabor, textura e odor; o distanciamento dos moradores dos grandes centros urbanos em relação aos alimentos; o hábito de cozinhar dentro de casa e a importância de conhecer os alimentos que são ingeridos; a informações nutricionais disponíveis nos rótulos dos alimentos; os problemas de saúde causados por consumo de altas quantidades de açúcar, de sal e de gordura, por exemplo. 


\section{A1) e-Mosaicos \\ Revista Multidisciplinar de Ensino, Pesquisa, Extensão e Cultura \\ do Instituto de Aplicação Fernando Rodrigues da Silveira (CAp-UERJ) \\ V. 10 - N. 23 - Janeiro-Abril de 2021 - ISSN 2316-9303}

DOI: $10.12957 / \mathrm{e}-\mathrm{mosaicos} .2021 .48433$

Figura 2. Alunos participando da atividade "Desvendando os Alimentos"

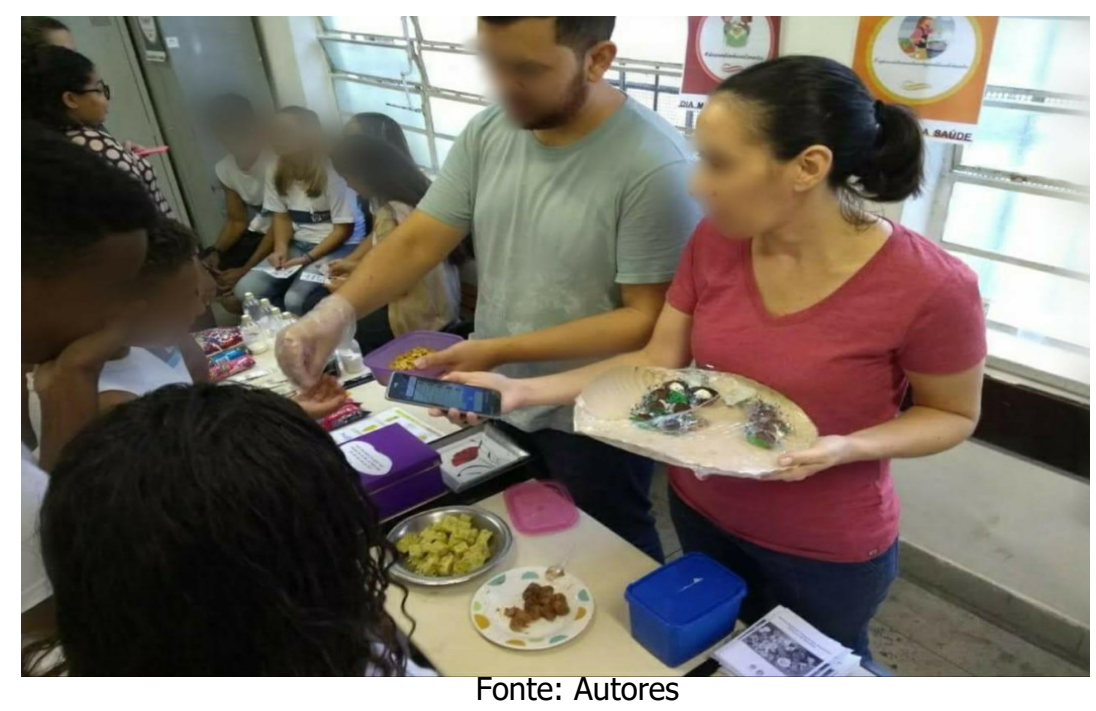

Essa atividade despertou um interesse imediato nos estudantes causado pelo estímulo visual, proporcionado pela exposição dos alimentos processados e ultraprocessados. A discussão sobre os limites diários de consumo de açúcares, gorduras e sódio não era de conhecimento da maioria, causando surpresa para grande parte dos estudantes. Os participantes se mostraram motivados a contarem sobre os hábitos alimentares da família, bem como problemas de saúde de familiares e conhecidos relacionados ao consumo dessas substâncias. Observou-se, também, que a maior preocupação dos estudantes foi sobre o efeito dos alimentos no ganho de peso, desconhecendo outros problemas de saúde. Os participantes, em geral, também demonstraram curiosidade em relação à tabela nutricional e à lista de ingredientes presentes nos rótulos, evidenciando desconhecer essas informações.

\section{Atividade 3) "Aproveitamento Integral dos Alimentos"}

A atividade consistiu em promover um espaço de reflexão e de diálogo com os estudantes sobre as relações sociais, históricas, afetivas e culturais que envolvem a alimentação. Buscamos problematizar: quem são as pessoas que cozinham em nossas casas? Quais as comidas favoritas e que lembranças trazem para nós? De onde vem os alimentos que compramos no mercado? Com base nesses questionamentos, resgatamos a ideia de que a comida não alimenta apenas o corpo, mas também nossa memória afetiva, nossa noção de pertencimento etc. Apresentamos o caminho do alimento - da colheita até o mercado - mostrando a quantidade de desperdício ao longo desse caminho. Problematizamos algumas oportunidades de diminuição do desperdício em casa e os 
DOI: $10.12957 / \mathrm{e}-\mathrm{mosaicos} .2021 .48433$

convidamos a ampliar o olhar para consumir partes dos alimentos considerados lixo, tais como talos, cascas e sementes.

Na sequência dessa discussão, oferecemos algumas preparações saudáveis com aproveitamento integral (brigadeiro preparado com banana, almôndega com casca de banana, bolinho de arroz com casca de abóbora e semente de abóbora temperada). Os participantes experimentaram os alimentos sem saber quais eram os ingredientes, sendo convidados a descobrir e avaliar o sabor. Além de destacar o valor nutricional de determinadas partes de alimentos estigmatizadas como lixo, convidamos os participantes a experimentar diferentes preparações em suas casas, com base em um caderninho de receitas distribuído ao final da atividade.

Essa atividade foi a que mais gerou indagações e questionamentos por parte dos estudantes, despertados pela curiosidade em relação aos alimentos servidos. Durante a atividade, foi comum os estudantes compartilharem informações sobre seus hábitos alimentares, lembranças afetivas em relação aos alimentos e às experiências culinárias. 0 compartilhamento deles sobre 0 ato de cozinhar trouxe riqueza para as discussões, estimulando-os a relembrar seus pratos preferidos, seu relacionamento com a cozinha, a frequência e as receitas que gostam de cozinhar.

A exposição e a degustação de preparações feitas com casca de alimentos, por exemplo, foram recebidas com surpresa, visto que foram comuns falas como "eu nunca pensei que desse para comer casca de banana". Alguns estudos destacam o desconhecimento das crianças e dos adolescentes em relação às potencialidades nutricionais, econômicas e ambientais do aproveitamento integral dos alimentos. Como forma de agregar nutrientes na alimentação e de reduzir a produção de resíduos, os autores apontam a escola como espaço apropriado para incentivar discussões a respeito desse tema com os estudantes e com os/as profissionais responsáveis pela produção da alimentação escolar (NUNES, 2009, p. 47; CARVALHO; BASSO, 2016, p. 70). Quando questionados se as preparações oferecidas poderiam ser consumidas nas merendas da escola ou em casa, os estudantes, em sua maioria, consideraram que teriam potencial de diminuir os custos e aumentar o valor nutricional da alimentação nesses espaços.

\section{TECENDO CONSIDERAÇõES: POTENCIALIDADES E DESAFIOS DA OFICINA}

De forma geral, nas três atividades, os alunos se integraram ativamente e se sentiram motivados a participar e a levantar questões sobre as discussões propostas. 0 fluxo de participantes era constante e eles se organizavam em grupos, o que proporcionava maior riqueza nos momentos de troca entre eles e nós, mediadores. Como um resultado positivo das atividades, destacou-se o entusiasmo dos estudantes quando expunham seus conhecimentos prévios sobre os assuntos abordados e a curiosidade para 
DOI: $10.12957 / \mathrm{e}-\mathrm{mosaicos} .2021 .48433$

participar das discussões propostas. A postura dialógica que estabelecemos com os estudantes contribuiu para a construção coletiva sobre os temas abordados, na medida em que valorizou os conhecimentos prévios dos alunos como ponto de partida, possibilitando, assim, uma aprendizagem significativa (MOREIRA, 1997, p. 2; SANTOS, 2005, p. 689). Desta forma, com relação ao tema central - alimentação e saúde - os alunos demonstraram interesse em conhecer melhor aquilo que consomem e entender 0 impacto da alimentação sobre seu corpo.

A aproximação dos alunos com aquilo que eles consomem foi um dos objetivos alcançados na atividade de extensão aqui relatada. A possiblidade de apresentar informações importantes (como a leitura de rótulos, por exemplo), juntamente com as problematizações e discussões enriquecidas com os conhecimentos prévios dos alunos, proporcionou um ambiente de troca que fomentou a construção de conhecimentos para subsidiar escolhas alimentares mais saudáveis. Um aspecto que chamou atenção, foi o fato de que além dos estudantes, as atividades também despertaram o interesse e a curiosidade de professores, coordenadores e merendeiras da escola.

Esse interesse se refletiu no convite para que participássemos de uma atividade planejada pela escola para celebrar o dia das mães. Como forma de alcançar mais efetivamente a vida dos estudantes, a coordenação sugeriu que apresentássemos as 3 atividades para as mães - sendo que o "Diário do corpo", por demanda da escola, foi adaptado para focar na discussão sobre bullying, automutilação e a necessidade de atenção na relação do adolescente com o próprio corpo. As três atividades despertaram bastante interesse das mães, que participaram com perguntas e trocas de experiência. Ao final, elas levaram para casa sementes para plantio e um livro de receita com preparações de aproveitamento integral de alimentos.

Em relação às atividades da oficina no Dia Mundial da Saúde, consideramos como o maior desafio lidar com o grande fluxo de alunos e de atividades do evento. Eram diferentes oficinas e atividades oferecidas por diferentes grupos naquele dia, o que gerou certa "ansiedade" nos alunos de percorrerem a maior quantidade de experiências. Com isso, não foi possível promover uma discussão mais aprofundada sobre as impressões dos alunos ao final da atividade. Além disso, é necessária a produção de uma quantidade maior de preparações, tornando mais complexa a organização da atividade. Outro desafio enfrentado pelo grupo diz respeito ao repensar a atividade do "Diário do Corpo", incorporando estratégias mais dinâmicas e lúdicas que deixem os estudantes mais à vontade para falar sobre a relação com o próprio corpo.

Como uma forma de registrar e divulgar essa experiência, vem sendo construído um site (https://trilhadaalimetacao.wordpress.com/) que disponibiliza informações sobre todas as atividades desenvolvidas com uma linguagem mais acessível e menos acadêmica, a fim de apresentar histórico e descrição das atividades, expor fotos dos eventos, 
DOI: $10.12957 / \mathrm{e}-\mathrm{mosaicos} .2021 .48433$

disponibilizar as receitas utilizadas e promover a divulgação do projeto de extensão. Além disso, oferece um espaço para comunicação que compartilha impressões, dúvidas e sugestões com os interessados na oficina, possibilitando maior alcance da mesma.

\section{Referências}

ACCIOLY, Elizabeth. A escola como promotora da alimentação saudável. Rio de Janeiro. Ciência em tela, v. 2, n. 2, p. 1-9, 2009.

AZEVEDO, Elaine de. Alimentação, sociedade e cultura: temas contemporâneos. Porto Alegre. Sociologias, v. 19, n. 44, p. 276-307, 2017.

BEZERRA, José Arimatea Barros. Alimentação e escola: significados e implicações curriculares da merenda escolar. Rio de Janeiro. Revista Brasileira de Educação, v. 14, n. 40, p. 103-115, 2009.

BIELEMANN, Renata M. et al. Consumo de alimentos ultraprocessados e impacto na dieta de adultos jovens. São Paulo. Revista de Saúde Pública, v. 49, p. 28, 2015.

BRASIL. Decreto no 7.272. Criação do Sistema Nacional de Segurança Alimentar e Nutricional - SISAN, de 25 de agosto de 2010.

BRASÍLIA. Fundo Nacional de Desenvolvimento da Educação (FNDE). O Programa Nacional de Alimentação Escolar (PNAE). Disponível em:

https://www.fnde.gov.br/index.php/programas/pnae . Acesso em: 29 jan. 2020

CAISAN. Câmara Interministerial de Segurança Alimentar e Nutricional. Plano Nacional de Segurança Alimentar e Nutricional: 2012/2015. -- Brasília, DF, 2011.

CARVALHO, Camila Campello; BASSO, Cristiana. Aproveitamento integral dos alimentos em escola pública no município de Santa Maria-RS. Santa Maria. Disciplinarum Scientia/ Saúde, v. 17, n. 1, p. 63-72, 2016

DEL CIAMPO, Luiz Antonio; DEL CIAMPO, Ieda Regina Lopes. Adolescência e imagem corporal. Rio de Janeiro. Adolescência e Saúde, v. 7, n. 4, p. 55-59, 2010. 
DOI: $10.12957 / \mathrm{e}-\mathrm{mosaicos} .2021 .48433$

FREITAS, Andréa Silva de Souza; COELHO, Simone Côrtes; RIBEIRO, Ricardo Laino. Obesidade infantil: influência de hábitos alimentares inadequados. Saúde \& Amb. Rev, Duque de Caxias, v. 4, n. 2, p.9-14, jul-dez. 2009.

GARCIA, Rosa Wanda Diez. Reflexos da globalização na cultura alimentar: considerações sobre as mudanças na alimentação urbana. Campinas. Revista de Nutrição, v. 16, n. 4, p. 483-492, 2003.

GONÇALVES, Fernanda Denardin et al. A promoção da saúde na educação infantil. Botucatu. Interface-Comunicação, Saúde, Educação, v. 12, n. 24, p. 181-192, 2008.

GONÇALVES, Vivianne Oliveira; MARTÍNEZ, Juan Parra. Imagem corporal de adolescentes: um estudo sobre as relações de gênero e influência da mídia. Goiás. Comunicação \& Informação, v. 17, n. 2, p. 139-154, 2014.

LOUZADA, Maria Laura da Costa et al. Alimentos ultraprocessados e perfil nutricional da dieta no Brasil. São Paulo. Revista de Saúde Pública, v. 49, p. 00-00, 2015.

MAEYAMA, Marcos Aurélio et al. Promoção da saúde como tecnologia para transformação social. Itajaí. Revista Brasileira de Tecnologias Sociais, v. 2, n. 2, p. 129-143, 2015.

MARTINS, Ana Paula Bortoletto et al. Participação crescente de produtos ultraprocessados na dieta brasileira (1987-2009). São Paulo. Revista de Saúde Pública, v. 47, p. 656-665, 2013.

MAUSS, Marcel. Ensaio sobre a dádiva, forma e razão da troca nas sociedades arcaicas. In: Sociologia e antropologia. v. 2. São Paulo: EPU/EDUSP, 1974.

MAZUR, Caryna Eurich; NAVARRO, Francisco. Insegurança alimentar e obesidade em adultos: Qual a relação?. Santa Maria. Saúde, v. 41, n. 2, p. 35-44, 2015.

MEIRELLES, Laércio. Soberania Alimentar, agroecologia e mercados locais. Agriculturas, Rio de Janeiro, p.11-14, set. 2004.

MONTEIRO, Carlos Augusto et al. Increasing consumption of ultra-processed foods and likely impact on human health: evidence from Brazil. Cambridge. Public Health Nutrition, v. 14, n. 1, p. 5-13, 2010. 
DOI: $10.12957 /$ e-mosaicos.2021.48433

MOREIRA, Marco Antonio. Aprendizaje significativo: un concepto subyacente. Actas del encuentro internacional sobre el aprendizaje significativo. Porto Alegre. UFRGS, v. 19, p. 44, 1997.

NUNES, Juliana Tavares. Aproveitamento integral dos alimentos: qualidade nutricional e aceitabilidade das preparações. 2009. 65 f. Monografia (Especialização em Qualidade de Alimentos). Universidade de Brasília, Brasília, 2009.

SANTOS, Ana Lilian Bispo dos; GUBERT, Muriel Bauermann; DEUS, Andressa Cristina Santos de. A insegurança alimentar grave está associada a fatores de risco para doenças crônicas não transmissíveis e doença cardiovascular no Distrito Federal. Rio de Janeiro. DEMETRA: Alimentação, Nutrição \& Saúde, v. 11, n. 4, p. 1017-1029, 2016.

SANTOS, Ligia Amparo da Silva. Educação alimentar e nutricional no contexto da promoção de práticas alimentares saudáveis. Campinas. Revista de Nutrição, v. 18, n. 5, p. 681-692, 2005.

SCHMITZ, Bethsáida de Abreu Soares et al. A escola promovendo hábitos alimentares saudáveis: uma proposta metodológica de capacitação para educadores e donos de cantina escolar. Rio de Janeiro. Cadernos de Saúde Pública, v. 24, p. s312-s322, 2008.

SILVA, Aline Oliveira de Brito et al. Relação da alimentação com surgimento precoce da obesidade e diabetes mellitus tipo 2 em crianças e adolescentes. Campinas. Revista Eletrônica Acervo Saúde, n. 18, p. e90-e90, 2019.

TRICHES, Rozane Márcia; SCHNEIDER, Sergio. Reconstruindo o "elo perdido": a reconexão da produção e do consumo de alimentos através do Programa de Alimentação Escolar no município de Dois Irmãos (RS). Campinas. Segurança Alimentar e Nutricional, v. 17, n. 1, p. 1-15, 2010.

VASCONCELOS, Sandra Mary Lima et al. Food Insecurity in Households of Patients with Hypertension and Diabetes. São Paulo. Int J Cardiov Scie, v. 28, n. 2, p. 114-121, 2015.

VERDE, Sara Maria Moreira Lima. Obesidade infantil: o problema de saúde pública do século 21. Fortaleza. Revista Brasileira em Promoção da Saúde, v. 27, n. 1, p. 1-2, 2014. 
DOI: $10.12957 / \mathrm{e}-\mathrm{mosaicos} .2021 .48433$

YOKOTA, Renata Tiene de Carvalho et al. Projeto" a escola promovendo hábitos alimentares saudáveis": comparação de duas estratégias de educação nutricional no Distrito Federal, Brasil. Campinas. Revista de Nutrição, v. 23, n. 1, p. 37-47, 2010.

Recebido em 13 de fevereiro de 2020 Aceito em 25 de fevereiro de 2021 de Aplicação Fernando Rodrigues da Silveira (CAp-UERJ) está disponibilizada sob uma Licença Creative Commons - Atribuição - NãoComercial 4.0 Internacional.

Os direitos autorais de todos os trabalhos publicados na revista pertencem ao(s) seu(s) autor(es) e coautor(es), com o direito de primeira publicação cedido à e-Mosaicos.

Os artigos publicados são de acesso público, de uso gratuito, com atribuição de autoria obrigatória, para aplicações de finalidade educacional e não-comercial, de acordo com o modelo de licenciamento Creative Commons adotado pela revista. 